\title{
Illeri derecede varus deformiteli dizlerde total diz protezi uygulaması
}

\section{Total knee prothesis in knees with severe varus deformity}

\author{
Kutay Engin Özturan, Yasin Emre Kaya \\ Bolu Abant İzzet Baysal Üniversitesi Tıp Fakültesi, Ortopedi ve Travmatoloji Ana Bilim Dalı, Bolu
}

\begin{abstract}
İleri derecede varus deformiteli dizlerin osteoartritinde kalıcı ve uzun etkili tedavi, total diz protezi (TDP) cerrahisidir. Bu dizlerin cerrahisinde yumuşak doku dengesinin sağlanması ve defektlerin onarımı önem taşır. Koronal plan dengesinin sağlanmasında medial yumuşak doku kılıfının gevşetilmesinde; klasik medial gevşetme, pie crusting (turta deseni), tibia redüksiyon osteotomisi, medial epikondiler osteotomi, yüzeyel iç yan bağın femoral orijininin gevşetilmesi ile eklem seviyesinde derin ve yüzeyel iç yan bağın kesilmesi kullanılabilir. Defektlerin onarımında ise; boyutuna bağlı olarak ilave kemik kesilmesi, çimento, çimento ve vida, kemik grefti (otogreft veya allogreft, blok veya morselize), metal, serbest trabeküler, poroz metafiziyel konik destekler ve kişiye özel üretilmiş protezler kullanılabilir. İmplantın kısıtlama miktarının azalması, kemik protez ara yüzündeki stresleri azaltır ve protezin ömrünü uzatır. Yeterli stabilite ve denge sağlanamıyorsa, kısıtlayıcı bileşenler artırılmalıdır.
\end{abstract}

Anahtar sözcükler: varus; diz deformitesi; gonartroz; total diz protezi
Total knee arthroplasty (TKA) surgery is a reliable and safe procedure with reproducible long-term results at severe varus deformity. The success of TKA depends in part on proper soft tissue management to balance the knee, restoration of neutral limb alignment and managing bone defects. Techniques used to mediolateral balance the severe varus knee during primary TKA include classical medial release, pie crusting, tibia reduction osteotomy, medial epicondylar osteotomy, femoral origin release of the superficial medial collateral ligament, release of the deep and superficial medial collateral ligaments at the joint level. In the repair of defects; depending on the size, more bone cutting, cement, cement and screw, bone graft (autograft or allograft, block or morselized), metal, free trabecular, porous metaphyseal conical supports and custom-made prostheses can be used. Decreasing component constraint reduces stresses at bone prosthesis interface and longevity of the prosthesis will be increased. If adequate stability and balance can not be achieved components constrained must be increased.

Key words: varus; knee deformity; gonarthrosis; total knee arthroplasty
T otal diz protezi (TDP) ileri evre diz osteoartritinde 10 yıllık başarı oranı, \%95'in üstünde olan mükemmel sonuçlara sahip ve güncelliğini koruyan bir tedavi seçeneğidir. ${ }^{[1]}$ Başarılı ve uzun ömürlü bir TDP üç faktöre bağlıdır; alt ekstremite diziliminin restore edilmesi, implantların uygun ve hatasız pozisyonda yerleştirilmesi, hassas ve doğru "gap (aralık)"dengesi.

Mekanik femoro-tibial açının $20^{\circ}$ 'den (tibio-femoral varus açısı $15^{\circ}$ ) fazla olduğu dizler ileri derecede varus deformiteli olarak kabul edilir. De Mulyder ve ark.'na göre mekanik dizilimde $3^{\circ}$ sapma normal olarak kabul edilmekte, $4^{\circ}-10^{\circ}$ evre $1,11^{\circ}-20^{\circ}$ evre $2,21^{\circ}-30^{\circ}$ evre 3 ve $30^{\circ}$ 'den büyük deformiteler evre 4 olarak sınıflandırılmaktadır. ${ }^{[2]}$ Bu dizlerde yapılacak protez cerrahisi sırasında mücadele edilmesi gereken iki ana problem kemik defektleri ve eklem aralığı (gap) dengesizliğine sebep olan kontraktür, laksite gibi yumuşak doku problemleridir (Şekil 1).

Illeri derece varus deformiteli dizlerde hastanın alt ektremitesi mutlaka bir bütün olarak değerlendirilmelidir. Dizin hareket açıklığı, eşlik eden fleksiyon veya rekurvatum deformitesi göz önünde bulundurulmalıdır. Hastanın yürüyüşünün değerlendirilmesi, ameliyat öncesi planlamada yer almalıdır. Yürüyüş paterni, varus thrust gözlemlenmelidir. Cerrahi öncesi değerlendirmede ayakta basarak ortoröntgenografileri, lateral ve Merchant grafileri de çekilmelidir. Bu grafilerde varus deformitesinin boyutu, alt ektremitelerin mekanik ve anatomik aksı (ekseni), distal femur valgus kesim açısı ve eklem oblikliği değerlendirilmelidir. Medialdeki defektin boyutu cerrahi öncesi tespit edilmeli ve defekt onarımında olası kullanılacaklar eksiksiz hazır olmalıdır.

İletişim / Contact: Prof. Dr. Kutay Engin Özturan • E-posta / E-mail: drkutay@gmail.com

ORCID iD: Kutay Engin Özturan, 0000-0001-9506-4370 • Yasin Emre Kaya, 0000-0002-5412-8355

Geliş / Received: 17 Temmuz 2021 • Kabul / Accepted: 15 Ağustos 2021 


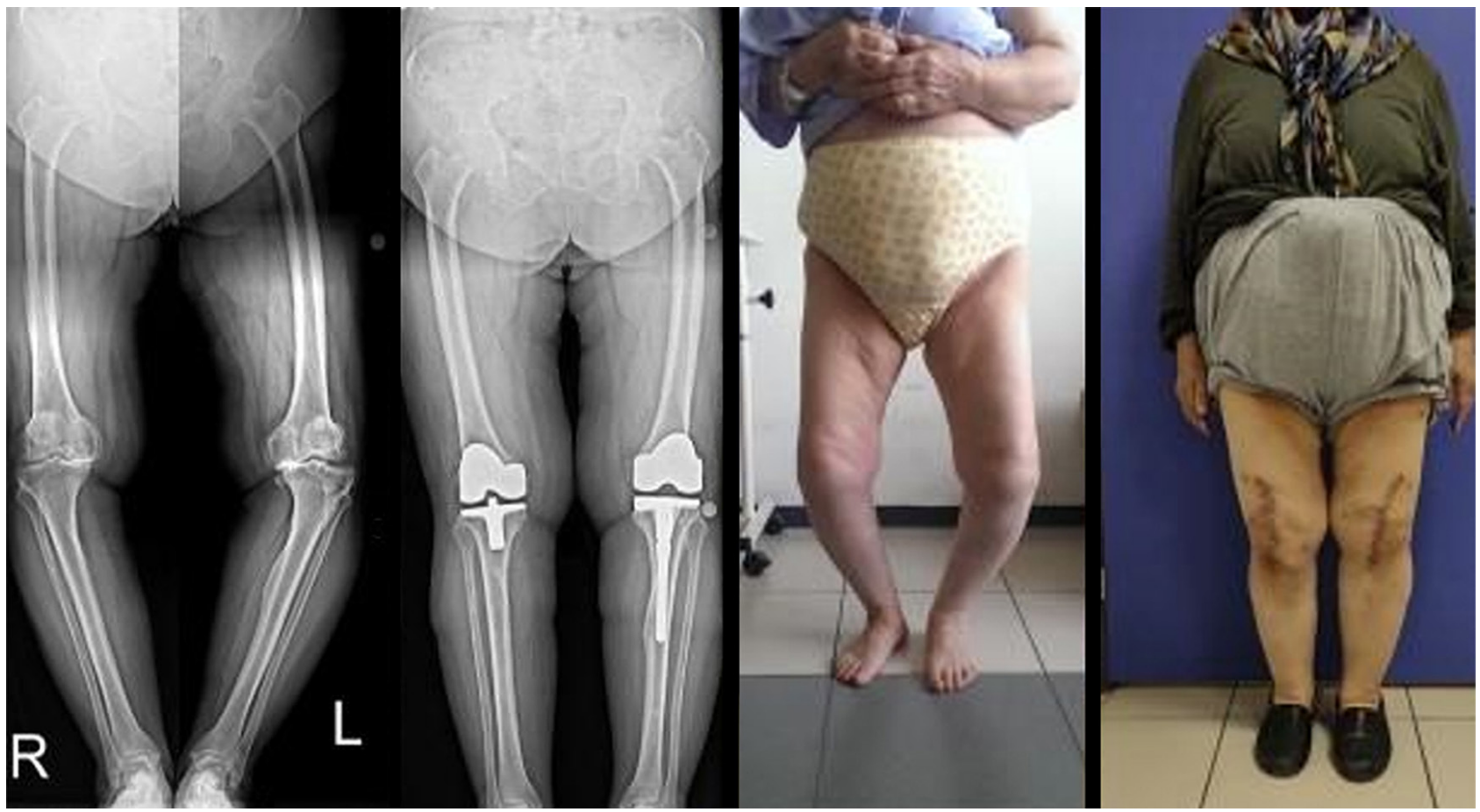

Şekil 1. İleri derecede bilateral varus deformiteli osteoartritte bağ kesen total diz protezi, medial kama ve sap uzatma uygulaması: Ameliyat öncesi ve sonrasına ait radyolojik ve klinik görüntüler.

İntramedüller kılavuzların kullanılmasında problem olmaması adına alt ektremite grafilerinde eğrilme (bowing) ve eklem dışı deformiteler dikkatlice değerlendirilmelidir. Tibia medialindeki aşıı aşınma ve eşlik eden tibianın arka tarafında kalan osteofitlere bağlı tibia pagoda şeklini alabilir. Bu durumda, cerrahi sırasında tibianın öne dislokasyonu zorlu olabilir. Lateral grafilerde tibia arkasındaki osteofitler ve aşınma şekli değerlendirilmelidir.

Basarak çekilen grafilerde nötral mekanik aksta $20^{\circ}$ 'den fazla fikse varus deviasyonu eklem içi veya eklem dışı sebeplere bağlı olabilir. Eklem içi sebepler; kartilaj veya kemik kaybı, stres kırıkları ve yanlış kaynamadır. Eklem dışı sebepler arasında konjenital veya metabolik hastalıklar (rickets, osteogenesis imperfecta, Blount), kötü pozisyonda kaynamış metafiziyel ve diyafiziyel kırıklar, kemik tümörleri, önceki distal femoral ve proksimal tibial osteotomiler sayılabilir. Eklem dışı deformiteler; femurda kollaterallerin köken aldığı epikondillerin proksimalinde, tibiada ise fibula başının distalinde yer alır. Ortoröntgenografide koronal planda mekanik aks deviasyonu (MAD), lateral distal femoral açı (LDFA), medial proksimal tibial açı (MPTA) ve center of rotation of angulation (CORA) ölçülür. Lateral distal femoral açının anormal olması deformitenin femurdan, MPTA açısının anormal olması ise deformitenin tibiadan kaynaklandığını ortaya koyar. Eklem dışı deformiteler tek, iki veya üç planlı olabilir. Center of rotation of angulation eklemden ne kadar uzaklaşırsa mekanik akstan sapma o kadar az olur. Bunun yanında dizden uzakta yer alan bir deformitede; ektremitede mekanik aks deviasyonu asla gözardı edilmemelidir. Tibia ya da femurdaki aynı $20^{\circ}$ 'lik koronal plan deformitesinin; ekleme her \%10'luk yaklaşması alt ekstremite diziliminde ilave $2^{\circ}$ 'lik bozulmaya sebep olur. ${ }^{[3]}$ Bu tip deformitelerde mekanik aks deviasyonu ne kadar fazla olur ise dizde osteoartrit gelişme ihtimali o kadar fazladır. Eklem dışı deformitelerin olduğu ileri varuslu dizlerdeki TDP cerrahisi sırasında deformite eklem içinden ve/veya eklem dışından düzeltilebilir. Eğer eklem dışı deformite koronal planda femurda $20^{\circ}$ 'den; tibiada ise $30^{\circ}$ 'den küçükse ve CORA metafiziyel bölgenin dışındaysa; eklem içi kompansatuvar düzeltme TDP cerrahisi sırasında sağlanabilir. ${ }^{[4]}$ Deformite eklem içinden düzeltilecekse; distal femur kesisi, lateral kollateral ligamentin lateral epikondildeki yapışma yerini tehlikeye sokmamalıdır. Femur mekanik aksına çekilen dik çizgi yapışma yerinin proksimalinde ise, eklem dışından düzeltici osteotomi yapılmalıdır. Tibiada ise; talus merkezinden distal tibia şaftı boyunca deformite distalinden çekilen çizgi tibia plato yüzeyinden geçiyorsa, cerrahi sırasında eklem dışı osteotomiye gerek kalmadan düzeltilebilir. Eklem seviyesinden düzeltilecek eklem dışı deformitelerinde; ekstansiyondaki ligament dengesi mutlaka göz önünde tutulmalıdır. Deformiteyi düzeltme adına telafisi güç eklem aralığı (gap) dengesizlikleri ile karşılaşılabilir. Ayrıca 
ileri derecelerdeki eklem içi düzeltmeler, aşırı yumuşak doku gevşetmelerini ve büyük defektlerle mücadeleyi gerektirir. Bunlara bağlı olarak seçilecek protezde kısıtlılık (constrained) miktarı ve sap uzatma kullanımı gerekebilir. Böyle olgularda aşırı kemik rezeksiyonu ve yumuşak doku gevşetmesi ve daha kısıtlayıcı protez kullanmak yerine deformiteye eklem dışı düzeltici ostetomi yapılabilir. Deformitenin eşlik ettiği ileri varuslu dizlerde cerrahi öncesi şablonla planlama protezlerin keel ve sap uzatmalarının yerleşimindeki olası problemleri ortaya koyar. Eklem dışı deformite nedeniyle protezlerin şablonlamasında problem tespit edilirse ya implant değiştirilir veya eklem dışı düzeltici osteotomi yapılabilir.

ileri derecede varus deformiteli dizlerde yumuşak doku dengesinin sağlanabilmesi TDP'de erken başarısızlığı azaltır. Bu dizlerde çapraz bağlar, tibia ve femur medialindeki osteofitler eksize edildikten, femur distal ve tibial kesiler yapıldıktan sonra varus-valgus stres testleri ile medial yumuşak doku kılıfındaki kontraktürün rijiditesi ve lateraldeki laksite değerlendirilir. Koronal plan dengesizlikleri sonucu instabilite, artmış polietilen aşınması, aseptik gevşeme, ağrı ve disfonksiyon ortaya çıkabilir.

\section{KORONAL PLAN YUMUŞAK DOKU DENGESi}

Bu dizlerde koronal plan dengesinin sağlanmasında medial yumuşak doku kılıfının gevşetilmesinde; Insall'ın tarif ettiği klasik medial gevşetme, pie crusting (turta deseni), tibia redüksiyon osteotomisi, medial epikondiler osteotomi, iç yan bağın (IYB) femoral orijininin gevşetilmesi ve eklem seviyesinde derin ve yüzeyel iYB'nin kesilmesi yöntemleri kullanılabilir. Ameliyat sırasında koronal planda medial ve lateral eklem aralığı (gap) farkı, ekstansiyon ve $90^{\circ}$ fleksiyonda 2 mm'den az olmalıdır. Yüzeyel iYB; medial yumuşak doku gevşetilmesinde final ve maksimal gevşemenin sağlandığı yapıdır. Bu yapı femoral orijininden, orta kısmından veya tibial yapışma yerinden gevşetilebilir.

\section{KLASIK MEDIAL GEVŞETME}

Fikse varus deformitesinin Insall'ın tarif ettiği klasik medial gevşetmesinde, ekstansiyonda proksimal anteromedial tibiadan subperiostal keskin bir disseksiyon yapılır. Periost elevatörü ile periostun altında kalınarak medialdeki tüm yapıları içerecek şekilde uzun bir medial yumuşak doku kılıfı kaldırılır. Gerekli olan gevşetme miktarına bağlı olarak, pes anserinus kısmen veya tamamen kaldırılabilir. Insall, medial eklem çizgisinden 8-10 cm'lik bir yumuşak doku kılıfı kaldırmayı önerir. Yumuşak doku kılıfının gevşetilmesi $8 \mathrm{~cm}$ 'den az olursa, gevşeme miktarı yetersiz kalabilir. ${ }^{[5,6]}$ Klasik gevşetme ekstansiyondakine kıyasla, fleksiyonda daha fazla gevşemeye sebep olup fleksiyonda medio-lateral planda instabilite açığa çıkabilir.

\section{PIE CRUSTING (TURTA DESENI)}

Geleneksel medial gevşetme yerine veya gevşetme ile kullanılabilen diğer bir yöntem de pie crustingdir (turta deseni). ileri derece varuslu dizlerde bu yöntem yeterli gelmezse, klasik subperiostal gevşetme eklenebilir. ${ }^{[7]}$

Bu yöntemde yüzeyel iYB gerim altında iken eklem seviyesinde iğne veya bistüri ile içten dışa ve sıralı olarak delikler açılır. 16, 18, 19 gaugelik iğneler veya 11,15 numara bistüri kullanılabilir. Kwak ve ark., iğne ile açılan deliklerin bistüriye göre daha sabit ve daha az yapısal değişiklere sebep olduğunu; bu nedenle iğne ile çok sayıda delik açmanın cerrahi sırasında medial gevşetmede daha güvenilir olduğunu önermiştir. ${ }^{[8]}$ Koronal planda fleksiyondaki medial-lateral (gap) eklem aralığı dengesizliklerinde fleksiyonda yapılacak pie crustingin (turta deseni) aşırı gevşeme ile sonuçlanır. ${ }^{[9]}$ Aynı çalışmada koronal planda ekstansiyondaki medial-lateral (gap) eklem aralığı dengesizliklerinde yüzeyel iYB'nin arka kısmı ve posteromedial köşe yapılarına pie crusting (turta deseni) yapılmış ve dengeli bir gevşeme elde edilmiştir. Koronal planda hem ekstansiyon hem fleksiyondaki medial-lateral (gap) eklem aralığı dengesizliklerinde öncelikle yüzeyel iYB'nin anterior kısmının gevşetilmesi, takiben yüzeyel iYB'nin arka kısmının ve posteromedial yapıların piecrusting (turta deseni) yapılması önerilir. Diz ekstansiyonda iken dizin posteromediali; posterior oblik ligament, semimembranozusun tendinöz kısmı ve posterior kapsül tarafindan desteklendiği ama diz fleksiyonda iken anteromedial destekleyici yapıların olmaması nedeniyle fleksiyondaki pie crustingin (turta deseni) aşırı gevşeme ile sonuçlandığı bildirilmiştir. ${ }^{[10]}$

Amundsen'e göre pie crusting (turta deseni)'deki delik sayısı ile yüzeyel iYY'deki uzama miktarı arasında bir korelasyon yoktur. Uzama miktarı hastaya özgüdür. Cerrahi sırasında siklik yüklenme yapılmadığı takdirde yüzeyel iYB'de aşırı gevşeme ile karşılaşılabilir. ${ }^{[11]}$ Pie crusting (turta deseni) $6-8 \mathrm{~mm}$ gevşemenin yeterli olduğu olgularda önerilir. ${ }^{[6]}$ Ön yüzeyel iYB ve arka yüzeyel iYB'nin selektif pie crustingi (turta deseni) daha dengeli bir fleksiyon ve ekstansiyon gevşemesi sağlar. Hem fleksiyon hemde ekstansiyonda gevşetme gerektiğinde her ikisine birden pie crusting (turta deseni) yapılır.

Mehdikhani, yüzeyel iYB'de selektif iğne ile çok sayıda delik açarak Insall'ın klasik gevşetme tekniğine kıyasla constrained insert kullanımını \%18'den \%8'e düşürmüştür. Bu teknikte osteofitler temizlenip kesiler yapıldıktan sonra derin iYB'nin arka kısmı, posteromedial kapsül, semimembranozus tendonu proksimal ve medial tibiadan eklem seviyesinden $1,5 \mathrm{~cm}$ distale kadar gevşetilir. Bu gevşeme yeterli gelmediği takdirde koronal planda ekstansiyondaki dengesizlik için 
medial yumuşak doku kılıfının posterioruna fleksiyondaki dengesizlik için ise anterioruna iğneleme yapılır. ${ }^{[12]}$

\section{IÇ YAN BAĞIN FEMORAL ORIJINININ GEVŞETILMESi}

Medialdeki osteofitler, derin IYB, posterior kapsül, semimembranozus tendonu gevşetilmesine rağmen devam eden koronal plan dengesizliklerinde ilave medial gevşetme için kullanılan diğer bir teknik de medial kollateral ligamentin femoral orijininin gevşetilmesidir. Fleksiyon pozisyonunda femura yapışan posteriordaki $1 / 3$ kısmı ilk olarak gevşetilir. Gevşemenin miktarına bağlı olarak, posterior $2 / 3$ veya tamamı gevşetilebilir. En önde yer alan IYB'nin femura bağlantısını devam ettiren fibröz yapılar gevşetilip femurdan ayrılmaz. Bu sayede kontrolsüz aşırı gevşetmenin önüne geçilmiş olur. ${ }^{[13]}$

\section{TiBIA REDÜKSIYON OSTEOTOMISI}

Bu yöntem Mullaji tarafından tanımlanmış olup $20^{\circ}$ üzerindeki ileri derecedeki varuslu hastalarda da başarılı sonuçlar elde edilmiştir. Posteromedialdeki derin medial kollateral ligament, posteromedial kapsül ve semimembranozus tendonu gevşetilir. ${ }^{[14]}$ Posteromedial tibia ve femur medialindeki osteofitler eksize edilir. Distal femur ve tibia kesileri yapıldıktan sonra ekstansiyonda koronal planda dengesizlik varsa tibianın posteromedial konveks kısmından osteotomla kademe kademe kemik eksize edilir. Ekstansiyonda mediolateral denge kontrol edilir. Hâlâ yüzeyel iYB aşırı gergin ve dengesizlik mevcut ise femoral komponentle uyumlu en küçük base plate; tibianın en lateraline yerleştirilir ve medialden bir kısım kemik daha eksize edilir. Bu sayede yüzeyel iYB indirekt olarak gevşetilmiş olur. Mullalji, bu yöntemin yeterli gelmediği nadir olgularda, distal yüzeyel iYYB'nin subperiostal gevşetilmesinin uygulandığını bildirmiştir. ${ }^{[14]}$

\section{MEDIAL EPIKONDILER OSTEOTOMi}

illeri varus deformitelerinde kullanılan diğer bir yöntemde Engh tarafından tanımlanmış olan medial epikondiler osteotomidir. Yüzeyel ve derin IYY'ye herhangi bir müdahalede bulunmadan medial epikondil distal ve posteriora kaydırılır. Diz $90^{\circ}$ fleksiyonda iken $1 \mathrm{~cm}$ genişliğinde, $4 \mathrm{~cm}$ uzunluğunda iYB'nin orijininin olduğu medial epikondil ostetomize edilir. Orijinal teknikte distal ve posteriora kaydırılan parça sütürlerle tespit edilir. Adduktor magnus yapışma yeri osteotomize edilen kemik fragmanında yer alır. Bu sayede ekstansiyonda epikondile proksimal stabilite desteği sağlanmış olur. ${ }^{[15]}$ Sütür ile tespitte $\% 40,7$ oranında fibröz union bildirilmiştir. Epikondilin vida ile tespitinde ise kemik kaynaması \%100 görülmüştür. Bunun yanında fibröz kaynama ağrı, hassasiyet ve instabiliteye sebep olmamaktadır. ${ }^{[16]}$

\section{KEMIK DEFEKTLERI SINIFLAMASI VE ONARIMI}

Primer TDP'deki kemik defektlerinin etiyolojisinde, artritik değişikliklere ikincil erozyon, travma, osteonekroz ve önceki osteotomiler yer alır. Revizyon cerrahisinin aksine defektin zemini sklerotiktir. Defektler santral ve periferik olarak ayrılmaktadır. İleri varuslu dizlerde defektlerin büyük çoğunluğu sınırlanmamış periferik defektlerdir. Bu tip dizlerde ortaya çıkan kemik kaybı açısal deformiteye ve instabiliteye yol açabilir. Tamir gerektiren defektlerin büyük çoğunluğu tibiada yer alır. Defektlerin sınıflandırılmasında çeşitli sınıflamalar vardır ama aralarında bir fikir birliği yoktur. Total diz protezi revizyonlarında kullanılan AORI (Anderson Orthopedic Research Institute) sınıflaması, primer diz protezi cerrahisindeki defektlerin de sınıflandırılmasında kullanılmaktadır (Tablo 1). ${ }^{[17]}$ Derinliği 5 mm'den fazla, tibial base platein $\% 40$ 'ından fazlasının tibia platosu tarafindan desteklenmediği ve tibial denemenin instabil olduğu tibia defektlerinde onarım gereklidir. Tibia mekanik aksına dik olacak şekilde tibia kesisi yapıldıktan sonra geride kalan defekt için; tibianın bir miktar daha kesilmesi, çimento, çimento ve vida, kemik grefti (otogreft veya allogreft, blok veya morselize), metal, serbest trabeküler, poroz metafiziyel konik destekler, kişiye özel üretilmiş veya tümör protezleri kullanılabilir. Aggarwal ve ark., AORI sınıflamasına göre primer diz protezi cerrahisinde defekt onarımını sınıflandırmıştır (Tablo 2). ${ }^{[18]}$ Defektlerin tedavisinde fikir birliği yoktur. Defektin tipine, boyutlarına ve cerrahın tercihine göre farklııı gösterir. Diğer kullanılabilecek tedavi yöntemleri aşağıda anlatılmıştır.

Tablo 1. AORI (Anderson Orthopedic Research Institute) kemik defektleri sınıflamasi ${ }^{[17]}$

\begin{tabular}{ll} 
Tip 1 (T1 ve F1) & $\begin{array}{l}\text { Stabiliteyi bozmayan minör kemik } \\
\text { defektleri var. }\end{array}$ \\
Tip 2A (T2A ve F2A) & $\begin{array}{l}\text { Bir femoral kondil/tibia platoda } \\
\text { komponent stabilitesi için onarılması } \\
\text { gerekli metafiziyel kemik hasarı ve } \\
\text { kansellöz kemik kaybı var. }\end{array}$ \\
Tip 2B (T2B ve F2B) & $\begin{array}{l}\text { Her iki femoral kondil ve tibial platoda } \\
\text { komponent stabilitesi için onarılması } \\
\text { gerekli metafiziyel kemik hasarı ve } \\
\text { kansellöz kemik kaybı var. }\end{array}$ \\
Tip 3 (T3 ve F3) & $\begin{array}{l}\text { Belirgin metafiziyel kemik hasarı ve } \\
\text { kansellöz kemik kaybı var. Femoral } \\
\text { kondil veya tibial platonun büyük kısmı } \\
\text { hasarlı. Kollateral bağ veya patellar } \\
\text { tendon ayrışması ile birlikte olabilir. }\end{array}$ \\
\hline T, tibia; F, femur. &
\end{tabular}

T, tibia; F, femur. 
Tablo 2. Primer diz protezi cerrahisinde karşılaşılan kemik defektleri ve bu defektlere yaklaşım ${ }^{[18]}$

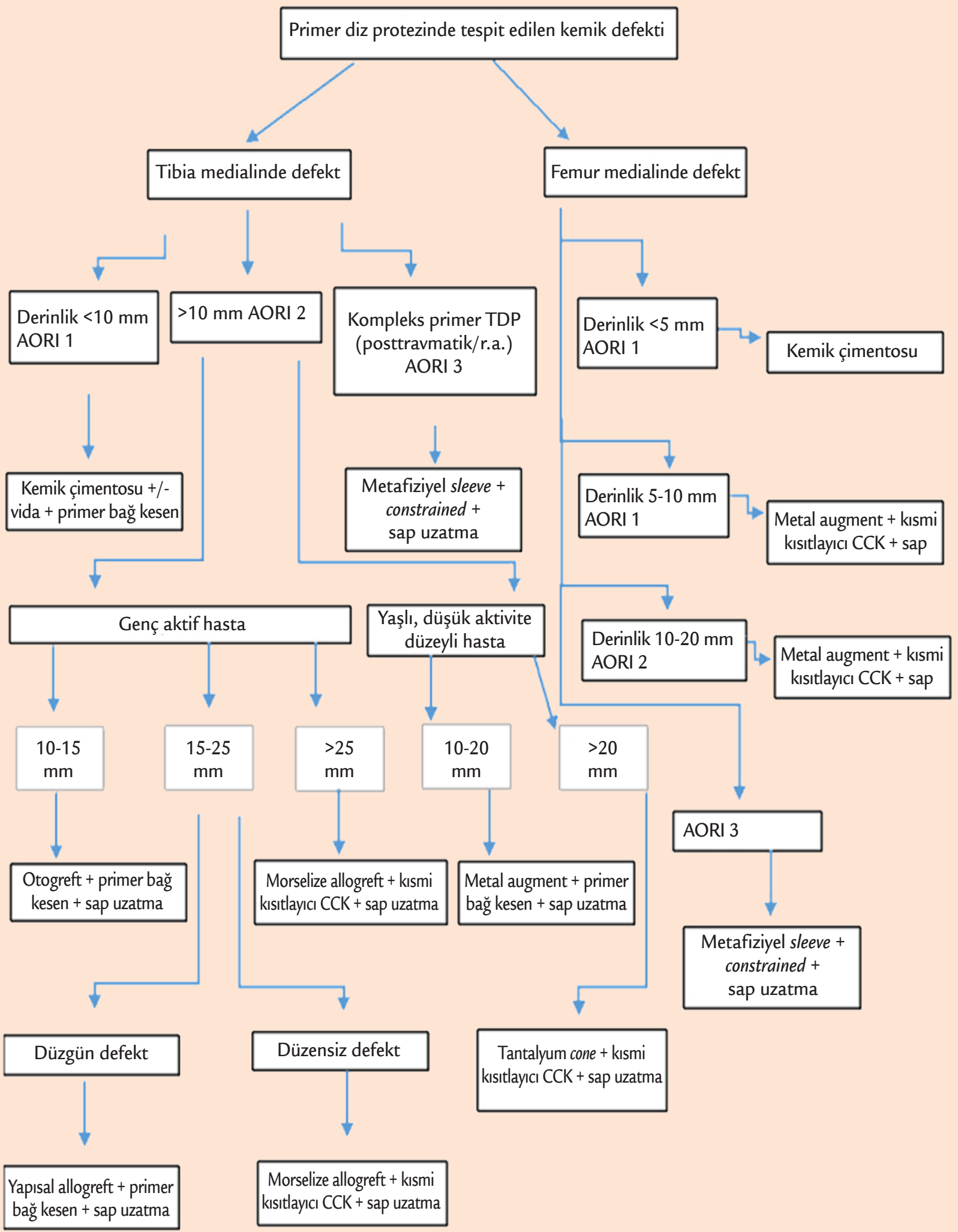

AORI, Anderson Orthopedic Research Institute; r.a., romatoid artrit; CCK, central constrained condylar. 


\section{DEFEKTIN ÇIMENTO VE VIDA ILE DOLDURULMASI}

Boyutu 5 mm'ye kadar olan defektler çimento ile doldurulabilir. Çimento, 5-10 mm arasındaki defektlerde tek başına kullanılmamalı; defekt, zeminine bir ya da iki vida yerleştirildikten sonra çimento ile doldurulmalıdır. Defektin, tibia platosunun koronal plan uzunluğuna oranı \%10'un altında olmalıdır. Çimento ve vidanın, metal destekler ile karşılaştırıldığında aksiyel ve varus yüklerine dayanımı daha düşüktür. Defekt 10 mm'den daha büyük ise, çimento kullanılması durumunda çimentoda fragmantasyon, mekanik instabilite, erken gevşeme ve çimentonun fazla miktarda olmasından ötürü termal nekroz oluşabilir.

\section{PROKSIMAL TIBIAA REDÜKSIYONU}

Lateral tibial platodan stylus ile ayarlanıp 8-10 mm yüksekliğinde tibia kesisi yapılır. Eğer defekt boyutlarına belirgin etkisi olacak ise $2 \mathrm{~mm}$ daha rezeksiyon yapılabilir ve daha kalın bir insert konur. Defekti ortadan kaldırmak ya da küçültmek adına daha fazla rezeksiyon yapılmamalıdır. Dorr ve ark., kemik rezeksiyonunun lateralde subkondral plağın en fazla $10 \mathrm{~mm}$, medialde ise 5 $\mathrm{mm}$ altına inilmemesini önermişlerdir. ${ }^{\left[{ }^{19]}\right.}$ Rezeksiyonun aşırı yapılması tibial komponentin küçülmesine, osseöz desteğin ve artan yüklere karşı destek alanının azalmasına sebep olur.

\section{DEFEKTIN GREFT ILE ONARIMI}

Yüksekliği 20 mm'den ve genişliği \%50 den daha küçük santral ve periferik defektlerde otogreft veya allogreft kullanılabilir. Otogreft, cerrahi sırasında: notch kesisinden, posterior kondil kesilerinden, lateral tibial platodan veya iliak krestten elde edilebilir; 10 mm'nin üzerinde blok greft elde etmek zordur ve kesilerden elde edilen greftler sklerotik olup greft niteliği taşımaması ve büyük defektlerde restorasyon alanını doldurmaya yetmemesi otogreft kullanımındaki kısıtlamalardır. Greftleme blok olarak veya morselize impaksiyon greftleme şeklinde uygulanır.

Greft implanta biyolojik destek sağlar ve uygulaması kolaydır. Greft rezorbe olmayıp kaynadığında; kalıcı, dayanıklı ve ilerideki revizyonlarda protez uygulamasına izin veren bir kemik stoğu elde edilmiş olur. Grefte aşırı yüklenmeyi engellemek için uygun dizilim ve tibial komponent pozisyonu sağlanmalıdır. Kaynama elde edildiğinde daha fizyolojik bir yük transferi ortaya çıkar. Allogreftlerde kendi içinde yapısal ve morselize olarak ikiye ayrilır.

Blok greftlemede greftin oturacağı lateral ve inferior yüzey, greft temasını sağlamak adına ve kanlanan kemiğe ulaşılması için osteotomize edilir. Blok greft yerleştirildikten sonra vida veya Kirschner telleri ile tespit edilir. Greftin oturacağı yüzey; kesi ve drilizasyon sonrası sklerotik ve kanlanmıyorsa, greft kullanılmamalıdır. Yine avasküler nekroz olgularında da greft kullanılmamalıdır. Greft zeminine laterale eğim verilmesi veya basamaklı osteotomi yapılması temas alanını, stabiliteyi ve greftin inkorpore olma oranını artırır. ${ }^{[14,19]}$

\section{IMPAKSIYON GREFTLEME}

Periferik ve santral defektler için kullanılabilir. Çevre sınırları belli olmayan (uncontained) defektlerde zemin bir miktar derinleştirilip korteks sağlam bırakılarak çevre duvar oluşturulur ve sınırları belli bir defekte çevrilir. Blok şeklindeki veya büyük kemik parçaları defekte çakılır. Bu yöntemde ilave tespit gerekmez. Diğer bir yöntemde greft zeminine oluklar açılıp tıkaç şeklinde greftler bu oluklara çakılır. Aradaki boşluk kısımlar morselize greft ile doldurulur. ${ }^{[20]}$

Morselize greftler tek başına santral ve periferik defektlerde kullanılabilir. Sugita ve ark., 25 mm'ye kadar derinlikteki sınırlandırılmamış periferik defektleri morselize greft ile restore etmişlerdir. Defekte yerleştirdikleri greftleri yerinde tutmak için bir metal mesh ve sap uzatma kullanmamışlardır. Medial yumuşak doku zarfının greftin dağılmasını engellediğini öne sürmüşlerdir. Bir yıl içinde tüm olgularda greft kaynamış, trabekülasyon görülmüş ve absorpsiyon ve çökme tespit edilmemiş̧ir. ${ }^{[21]}$ Periferal defekt 25 mm'nin üzerinde ise, morselize greft kullanıldığında vida ile tutturulmuş metal mesh ve sap uzatma kullanılması önerilir. ${ }^{[22]}$

\section{YAPISAL KEMIK GREFTLERi}

Greft şeklinin defekt bölgesiyle uyuşması avantajdır. Tüm kondilin \%40'ına kadar defektif olduğu ve 25 mm'ye kadar derinliği olan defektlerde kullanılır. Yapısal greft olarak femur başı, distal femur veya proksimal tibial segment kullanılabilir. Yapısal allogreftler implant için stabil yük taşıyan düzgün bir yüzey oluşturur. Oblik ve düzensiz yüzey, greft ile kemik temasını ve stabiliteyi artırmak adına, dikdörtgen hale getirilmelidir. Greftin boyutunun ve şeklinin defekte spesifik seçilmesi önemlidir. Sap uzatma grefte binen stresleri azaltmak için yapısal greftlerle birlikte kullanılmalıdır.

\section{METAL DESTEKLER}

\section{Metal Blok ve Kamalar}

İyi yük transferi sağlayan stabil implantlardır. Uygulanması kolay ve hızlıdır. Hemen yük verilebilir. Anatomik eklem çizgisi restorasyonuna ve fleksiyon ekstansiyon dengesinin sağlanmasına olanak tanır. 


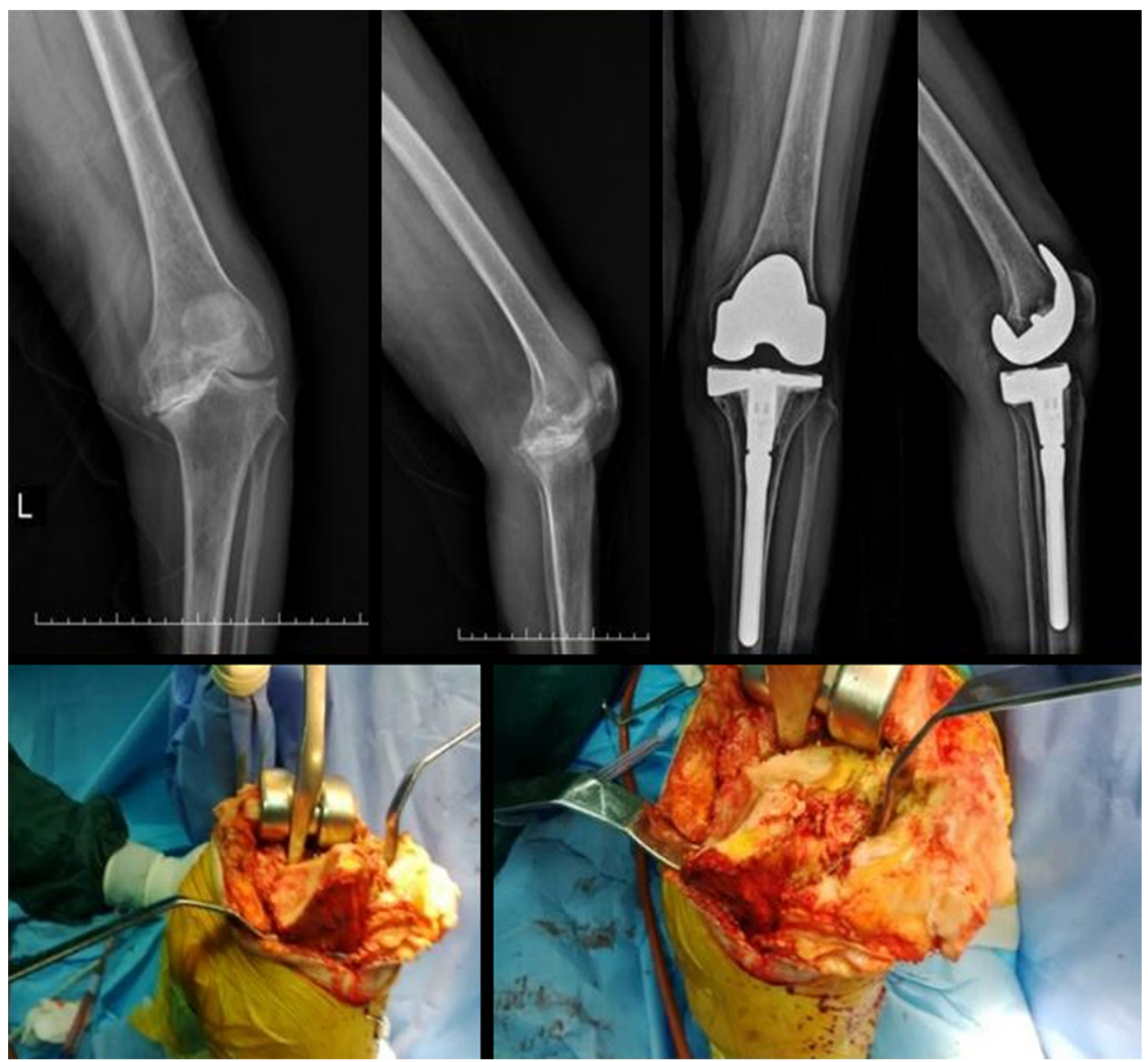

Şekil 2. Tibia medial plato epifiz ve metafizde ileri derecede sınırlanmamış kemik defekti. Defektin metal kama ve sap uzatma ile onarımı: Ameliyat öncesi ve sonrasına ait radyolojik görüntüler (üst sıra); ameliyat esnasına ait görüntüler (alt sıra).

Değişik boy ve şekillerde üretilirler. Bu cerrahın olgu sırasındaki tercih seçeneklerini artırır. Metal destek 5 mm'den daha kalın kullanılacaksa veya defekt tabanındaki kemik kalitesi bozuk ve yetersiz ise sap uzatma kullanılması önerilir. ${ }^{[23]}$ Tibial base plate vida veya çimento ile tespit edilebilir. Defekt boyutuna bağlı olarak birden fazla üst üste kullanılabilir. İkinci blok, tibial komponente vidalanmış metal desteğe çimento ile tespit edilir. Metal destekler $20 \mathrm{~mm}$ derinliğe kadar olan periferik defektlerde kullanılabilir (Şekil 2). ${ }^{[24]}$ Dikdörtgen metal destekler kama şeklinde olanlara göre biyomekanik olarak daha stabildir ve kemik-metal destek ara yüzündeki makaslayıcı kuvvetler kama şeklinde olanlara göre daha azdır. Torsiyonel yüklerin doğrudan iletilmesini sağlar. Bunun yanında dikdörtgen metal desteklerin yerleştirilebilmesi için daha fazla kemik kesisine ihtiyaç duyulur.

Çift dikdörtgen blok kullanımında distaldeki blok sap uzatma ile uyum sağladığı ölçüde küçültülebilir. Bu sayede implant protrüzyonu, yumuşak doku irritasyonu ve ağrı azaltılmış olur. Yapısal allogreftlerle karşılaştırıldığında hastalık bulaşma riski, kaynamama, kırılma, kötü pozisyonda kaynama, rezorpsiyon ve çökme ihtimali yoktur. Takiplerde metal desteklerin altında radyolusen çizgiler değişik oranlarda görülmektedir. Ama uzun dönem takiplerde bu çizgilerin ilerleyici olmadığı ve çökme (subsidence) ve tibial komponentte gevşeme ile ilişkisi olmadığı bildirilmiştir. ${ }^{[25]}$ illerideki revizyonlarda kemik stoğu problemi nedeniyle daha yaşlı ve düşük aktivite düzeyli hastalarda kullanılması uygundur.

\section{Poroz Metafiziyel Konik Destekler ve Serbest Trabeküler Metal Destekler (Sleeve ve Cone)}

Poroz metafiziyel konik destek ve serbest trabeküler metal desteklerin kullanılmasının amacı sadece defekti doldurmak değil aynı zamanda implant için stabil bir yüzey oluşturmaktır. Tibia kesisi sonrası kemik stoğu 1 'inci bölgede (epifiz) yeterli ise tibial komponentin tespiti kolaydır. Ama AORI tip 2 ve 3'te epifize tespit yapılamaz çünkü epifizde belirgin kayıp vardır. Bu 


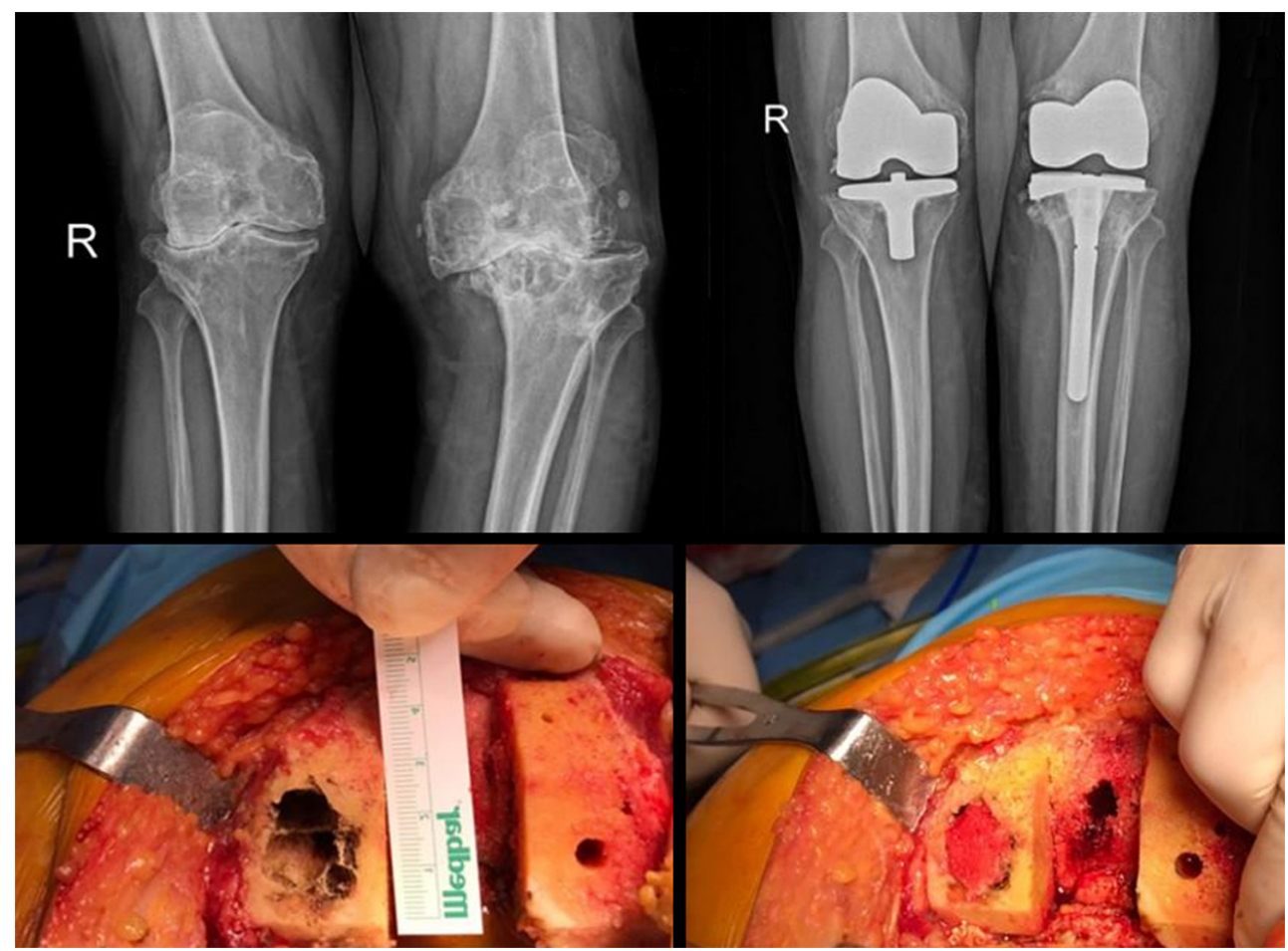

Şekil 3. İleri derecede varuslu dizde medial kondilde kist ve kistin greftle onarımı: Ameliyat öncesi ve sonrasına ait röntgenler (üst sıra); ameliyat esnasındaki klinik görüntüler (alt sıra).

durumda 2'nci ve 3'üncü bölgeye tutunum gereklidir. Poroz metafiziyel konik destekler bu defektlerde kullanılabilir. Üçüncü bölgeye tespiti için çimentolu veya çimentosuz sap uzatma kullanılır. Birinci bölge desteğinin çok az olduğu AORI tip $2 b$ ve 3 olduğu postravmatik artritlerde veya ciddi osteoporoz ve kemik kaybının eşlik ettiği romatoid artritli hastalarda poroz metafiziyel konik destekler iyi bir seçenektir. ${ }^{[18]}$

Yirmi milimetrenin üzerindeki AORI tip $2 b$ ve 3 defektlerin olduğu ileri evre varuslu dizlerde tantalyum serbest trabeküler metal destekler kullanılabilir. ${ }^{[26]} \mathrm{Bu}$ destekler hızlı bir kemik içine büyüme (ingrowth) sağlayan modüler çatı implantları (scaffold) olarak görev yapar. Trabeküler metal ile karşılaştırıldığında 2-3 kat fazla poroziteye ve ideal por ölçüsüne sahiptir. Young modülüsü (modulus of elasticity) düşük olduğundan güç kalkanı etkisine (stress shielding) sebep olmadan yük transferi sağlar. Defektlerde bozulmuş yapısal bütünlüğün oluşturulmasını sağlar, osteo-entegrasyonu kolaylaştırır. İmplant için çok iyi bir aksiyel destek sağlar. Serbest trabeküler metal destekler ile kemik arasındaki boşluk greftlenebilir. Poroz metafiziyel konik destekler ve serbest trabeküler metal destekler, pahalı implantlardır. Ayrıca solid bir osteo-entegrasyon meydana geldiği için bu implantları revizyon gerektiğinde sökmek çok zordur. Genç hastalarda kullanımı tartışmalıdır.

\section{IMPLANT SEÇIMi}

Illeri derecede varus deformiteli dizlerde kısıtlayıcılık (constrained) miktarı ne kadar az olursa kemik protez ara yüzündeki streslerde o oranda azalır ve implantın gevşeme olasılığı düşer. Standart bağ koruyan, bağ kesen, medial pivot total diz protezleri ile dengeli ve stabil bir diz elde edilemiyorsa, kısıtlayıcı seviyesi daha yüksek implantlara geçilmelidir. Kısıtlama artırımı koronal plan ligament dengesizliğinin gevşetme ve diğer prosedürler sonrası sağlanamaması, medialdeki derin defekte bağlı yüzeyel iYB'nin yetersizliği ve gevşetme prosedürleri sonrası koronal planda medial eklem aralığının beklenenden çok fazla artması durumunda yapılır.

İleri varuslu zor dizlerde kullanılacak implantın kısıtlayıcılığı, kollateral ligamentin bütünlüğüne ve dengesine ve kemik kayıplarının derecesine bağlıdır. AORI tip 1 defektlerde kollateral ligamentler sağlamsa bağ kesen implant kullanılabilir. Laskin ve ark., koronal planda $15^{\circ}$ 'nin üzerinde varus deformitesi olan dizlerde bağ koruyan implantların kullanılması durumunda revizyon oranının arttığını bildirmişlerdir. ${ }^{[27]}$ Tip 2 a kemik defektlerinde kollateraller sağlam ve denge iyi ise metal destekler ve/veya greft ile beraber bağ kesen sap uzatmalı bir implant seçilebilir (Şekil 3). 
Tip 2 defektlerde kollateral ligament zayıflığında greft veya metalik destekler kısmi kısıtlayıcı (semiconstrained) bir implant ve sap uzatma ile beraber kullanılmalıdır. Santral kısıtlı tasarımlar (Central Constrained Condylar-CCK) koronal plan ve rotasyonel stabiliteyi artırır. Tip 3 defektlerde kollaterallerin bütünlüğünün devamına bağlı olarak; santral kısıtlı veya rotating menteşeli implantlar arasında karar verilir.

Santral kısıtlı protezler sap uzatma ile beraber kullanılmalıdır. Bu uzatma epifiziyel ve metafiziyel kemiğe binen aşırı yükün diyafize aktarılması için gereklidir. Santral kısıtlı implantlar sap uzatma olmadan kullanıldığında üç kat daha fazla aseptik gevşemeye uğradığı gösterilmiştir. ${ }^{[28]}$ Santral kısıtlı protezlerin dezavantajları pahalı olması ve daha erken gevşemesidir.

illeri derecede varus deformiteli dizlerde medial gevşetmelere rağmen koronal dengenin tam olarak sağlanamadığı hafif koronal instabiliteli olgularda orta düzey kısıtlı (mid-level constrained) implantlar da kullanılabilir. Santral kısıtlı protezlere kıyasla daha az kısıtlayıcı olmakla birlikte daha geniş postu sayesinde birkaç derece koronal varus-valgus lift-offu ve rotasyonu engeller. Beş yıllık takiplerde $\% 97$ başarı oranı bildirilmiştir. ${ }^{[29]}$

\section{KAYNAKLAR}

1. American Joint Replacement Registry. Annual Report. Rosemont, IL. American Academy of Orthopaedic Surgeons (AAOS); 2019. https://www.aaos.org/aaos-home//newsroom/press-releases/ american-joint-replacement-registry-releases-2019-annual-report/

2. De Muylder J, Victor J, Cornu O, Kaminski L, Thienpont E. Total knee arthroplasty in patients with substantial deformities using primary knee components. Knee Surg Sports Traumatol Arthrosc 2015;23(12):3653-9. Crossref

3. Wolff AM, Hungerford DS, Pepe CL. The effect of extraarticularvarus and valgus deformity on total knee arthroplasty. Clin Orthop Relat Res 1991;(271):135-51. Crossref

4. Paley D. Principles of Deformity Correction. New York: Springer; 2002. https://www.springer.com/gp/book/9783642639531

5. Yasgur DJ, Scuderi GR, Insall JN. Medial release for fixedvarus deformity, Chapter 3. New York: Springer-Verlag; 2002. p.25-40. Crossref

6. Mihalko WM, Saleh KJ, Krackow KA, Whiteside LA. Soft tissue balancing during total knee arthroplasty in the varus knee. J Am Acad Orthop Surg 2009;17(12):766-74. Crossref

7. Mihalko WM, Woodard EL, Hebert CT, Crockarell JR, Williams JL. Biomechanical validation of medial pie-crusting for soft-tissue balancing in knee arthroplasty. J Arthroplasty 2015;30(2):296-9. Crossref

8. Kwak D-S, In Y, Kim TK, Cho HS, Koh IJ. The pie-crusting technique using a blade knife for medial collateral ligament release is unreliable in varus total knee arthroplasty. Knee Surg Sports Traumatol Arthrosc 2016;24(1):188-94. Crossref

9. Koh IJ, Kwak D-S, Kim TK, Park IJ, In Y. How effective is multiple needle puncturing for medial soft tissue balancing during total knee arthroplasty? A cadaveric study. J Arthroplasty 2014;29(12):2478-83. Crossref

10. LaPrade RF, Engebretsen AH, Ly TV, Johansen S, WentorfFA, Engebretsen L. The anatomy of the medial part of the knee. J Bone Joint Surg Am 2007;89(9):2000-10. Crossref
11. Amundsen $\mathrm{SH}$, Meyers $\mathrm{KN}$, Wright $\mathrm{TM}$, Westrich $\mathrm{GH}$. Variability in elongation and failure of the medial collateral ligament after pie-crusting with 16- and 18-gauge needles. J Arthroplasty 2018;33(8):2636-9. Crossref

12. Mehdikhani GK, Moreno MB, Reid JJ, Nieves AdP, Lee Y-Y, Della Valle AG. An algorithmic, pie-crusting medial soft tissue release reduces the need for constrained inserts patients with severe varus deformity undergoing total knee arthroplasty. J Arthroplasty 2016;31(7):1465-9. Crossref

13. Lee S-Y, Yang J-H, Lee Y-I, Yoon J-R. A Novel Medial Soft Tissue Release Method for Varus Deformity during Total Knee Arthroplasty: Femoral Origin Release of the Medial Collateral Ligament. Knee Surg Relat Res 2016;28(2):153-60. Crossref

14. Mullaji AR, Padmanabhan V, Jindal G. Total knee arthroplasty for profound varus deformity: technique and radiological results in 173 knees with varus of more than 20 degrees. J Arthroplasty 2005;20(5):550-61. Crossref

15. Engh GA. The difficult knee: severe varus and valgus. Clin Orthop Relat Res 2003;416:58-63. Crossref

16. Sim JA, Na YG, Go JY, Lee BK. Clinical and radiologic evaluation of medial epicondylar osteotomy for varus total knee arthroplasty. Knee 2018;25(1):177-84. Crossref

17. Engh GA. Bone defect classification. In: Engh GA, Rorabeck $\mathrm{CH}$, editors. Revision Total Knee Arthroplasty. Baltimore, Md, USA: Lippincott Williams \& Wilkins; 1997. p.63-120.

18. Aggarwal AK, Baburaj $\mathrm{V}$. Managing bone defects in primary total knee arthroplasty: options and current trends. Musculoskelet Surg 2021;105(1):31-8. Crossref

19. Dorr LD, Ranawat CS, Sculco TA, McKaskill B, Orisek BS. Bone graft for tibial defects in total knee arthroplasty. Clin Orthop 1986;(205):153-65. Crossref

20. Watanabe W, Sato K, Itoi E. Autologous bone grafting with out screw fixation for tibial defects in total knee arthroplasty. J Orthop Sci 2001;6(6):481-6. Crossref

21. Sugita $T$, Aizawa $T$, Miyatake $N$, Sasaki A, Kamimura $M$, Takahashi A. Preliminary results of managing large medial tibial defects in primary total knee arthroplasty: autogenous morcellised bone graft. Int Orthop 2017;41(5):931-7. Crossref

22. Kharbanda $Y$, Sharma M. Autograft reconstructions for bone defects in primary total knee replacement in severe varus knees. Indian J Orthop 2014;48(3):313-8. Crossref

23. Lee JK, Choi $\mathrm{CH}$. Management of tibial bone defects with metal augmentation in primary total knee replacement: a minimum fiveyear review. J Bone Joint Surg Br 2011;93-B(11):1493-6. Crossref

24. Hockman DE, Ammeen D, Engh GA. Augments and allografts in revision total knee arthroplasty: usage and outcome using one modular revision prosthesis. J Arthroplasty 2005;20(1):35-41. Crossref

25. Yamanaka H, Goto K, Suzuki M. Total knee arthroplasty for rheumatoid arthritis patients with large tibial condyle defects. J Orthop Surg (Hong Kong) 2012;20(2):148-52. Crossref

26. You JS, Wright AR, Hasegawa I, Kobayashi B, Kawahara M, Wang J, Nakasone CK. Addressing large tibial osseous defects in primary total knee arthroplasty using porous tantalum cones. Knee 2019;26(1):228-39. Crossref

27. Laskin RS. The Insall Award: Total knee replacement with posterior cruciate ligament retention in patients with a fixed varus deformity. Clin Orthop Relat Res 1996;331:29-34. Crossref

28. Mancino F, Falez F, Mocini F, Sculco PK, Maccauro G, De Martino I. Is varus-valgus constraint a reliable option in complex primary total knee arthroplasty? A systematic review. J Orthop 2021;24:201-11. Crossref

29. Crawford DA, Law JI, Lombardi AV, Berend KR. Midlevel constraint without stem extensions in primary total knee arthroplasty provides stability without compromising fixation. J Arthroplasty 2018;33(9):2800-3. Crossref 